\title{
Mapeamento da vulnerabilidade à contaminação de um sistema aquífero cristalino no município de Redenção/CE
}

A escassez hídrica se caracteriza como um dos principais problemas do semiárido brasileiro. Apesar da grande importância ambiental que os recursos hídricos apresentam, a cada dia estes vem passando por um intenso processo de degradação e contaminação. Nessa perspectiva a pesquisa tem como objetivo mapear as áreas vulneráveis à contaminação hídrica de um sistema aquífero localizado na serra Olho d'água dos Constantinos no município de Redenção (CE). Para isso utilizou-se o método GOD (Groundwater hydraulic confinement, Overlaying strata, Depth to groundwater table) para identificar a vulnerabilidade natural do aquífero, Avaliação de Impactos Ambientais (AIA) nas nascentes, por meio de parâmetros macroscópicos relacionado ao uso antrópico e medidas de conservação nas nascentes, e o mapeamento das áreas suscetíveis a contaminação, por meio do cruzamento da vulnerabilidade natural com as cargas contaminantes identificadas in loco. Identificou-se que o uso da água se destina principalmente as atividades domésticas (45,5\%) e ao consumo humano (36\%). Em relação ao grau de preservação das nascentes, observou-se que a maioria foram classificadas em péssimo e ruim estado de conservação (55,5\%). A vulnerabilidade natura classificou-se em inexistente e baixa, com índice GOD de 0,0 a 0,11. As principais fontes de contaminação mapeadas foram agricultura, efluentes domésticos e as edificações, resultando em duas áreas com alto risco de contaminação hídrica. Desse modo, conclui-se que os resultados apresentados corroboram para uma análise situacional do recurso hídrico, indicando as áreas que mais necessitam de cuidados, para que assim, possa evitar a degradação e contaminação do recurso tão necessário a comunidade e de grande importância ambiental.

\section{Mapping from vulnerability to contamination of a crystalline aquifering system in the city of Redenção/CE}

Water scarcity is characterized as one of the main problems in the Brazilian semiarid region. Despite the great environmental importance that water resource present, each day they are going through an intense process of degradation and contamination. In this perspective, the research aims to map the areas vulnerable to water contamination of an aquifer system located in the Serra Olho d'água dos Constantinos in the municipality of Redenção (CE). For this, the GOD method (Groundwater hydraulic confinement, Overlaying strata, Depth to groundwater table) was used to identify the natural vulnerability of the aquifer, Environmental Impact Assessment (EIA) in the springs, through macroscopic parameters related to anthropic use and measures of conservation in the springs, and the mapping of areas susceptible to contamination, by crossing the natural vulnerability with the contaminating loads identified in loco. It was identified that the use of wate is mainly intended for domestic activities (45.5\%) and human consumption (36\%). Regarding the degree of preservation of the springs, it was observed that most were classified as poor and poor state of conservation (55.5\%). Natural vulnerability was classified as non-existent and low, with a GOD index of 0.0 to 0.11 . The main sources of contamination mapped were agriculture, domestic effluents and buildings, resulting in two areas with a high risk of water contamination. Thus, it is concluded that the results presented corroborate for a situational analysis of the water resource, indicating the areas that most need care, so that, thus, it can avoid the degradation and contamination of the resource so necessary to the community and of great environmental importance.

Keywords: Groundwater; Semiarid; Degradation; Water Resources; Geoprocessing.

Topic: Uso de Recursos Naturais

Reviewed anonymously in the process of blind peer

Antonio Patrick Meneses de Brito

Universidade da Integração Internacional da Lusofonia Afro-Brasileira, Brasil http://lattes.cnpq.br/1438594906771448

http://orcid.org/0000-0002-8473-2617

patrickmeneses675@gmail.com

Ítalo Magno de Melo Santos

Universidade da Integração Internacional da Lusofonia Afro-Brasileira, Brasil http://lattes.cnpq.br/4960651222607037

http://orcid.org/0000-0002-9083-8450

iitalomagno@gmail.com

Rafaella da Silva Nogueira (id

Universidade da Integração Internacional da Lusofonia Afro-Brasileira, Brasil http://lattes.cnpq.br/5709447822168454

http://orcid.org/0000-0001-7540-1173

rafaellanogueira@unilab.edu.br

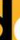

DOI: 10.6008/CBPC2318-2881.2021.002.0014
Received: 08/03/2021

Approved: 22/05/2021
Referencing this:

BRITO, A. P. M.; SANTOS, I. M. M.; NOGUEIRA, R. S.. Mapeamento da vulnerabilidade à contaminação de um sistema aquífero cristalino no município de Redenção/CE. Nature and Conservation, v.14, n.2, p.145-159, 2021. DOI: http://doi.org/10.6008/CBPC23182881.2021.002.0014 


\section{INTRODUÇÃO}

A escassez hídrica é um dos principais problemas presente no semiárido brasileiro. Apesar da grande importância ambiental que os recursos hídricos apresentam, a cada dia estes vem passando por um intenso processo de degradação e contaminação. A demanda de água para a agricultura, a dessedentação animal e o consumo humano são um dos grandes desafios para gestão dos recursos na região, principalmente quando se localizam em áreas rurais que muitas vezes não detém de abastecimento público regular (LIMA, 2020).

Em consequência da degradação e poluição sobre os recursos fluviais e consequente diminuição desses recursos, as águas subterrâneas se caracterizam como uma alternativa promissora para suprir essa carência. Dessa forma as águas subterrâneas tornam-se economicamente importantes para as comunidades semiáridas, podendo ocorrer como única forma de obtenção desse precioso e indispensável bem. Contudo, é importante salientar que os mananciais por onde afloram estão sujeitos a diversas formas de degradação seja pelo mal-uso ou por contaminação (AGRIZZI et al., 2018).

Para Pieroni et al. (2019) dentre os mananciais com fluxo jorrante, as nascentes são as fontes de água que abastecem as bacias hidrográficas sendo classificadas como perene ou sazonais. Essas unidades são as mais utilizadas para captação da água, onde as principais destinações são consumo humano, explosão industrial e atividade agropecuária (HIRATA et al., 2010). Ressalta-se que as nascentes são os elementos das APP's úmidas mais susceptíveis a vulnerabilidade, tanto por suas características biogeoquímicas como por uso humano indiscriminado (BRITO et al., 2019).

A vulnerabilidade à contaminação hídrica subterrânea é definida como o conjunto de características intrínsecas dos estratos que separam o aquífero saturado da superfície do solo, o que determina sua suscetibilidade a sofrer os efeitos adversos de uma carga contaminante aplicada na superfície (FOSTER, 1987). Assim, o estudo da vulnerabilidade torna-se indispensável para evitar contaminações no recurso. Foster et al. (2003) desenvolveu uma metodologia de avaliação da vulnerabilidade natural das águas subterrâneas, o método GOD, que indica a probabilidade de contaminação de um aquífero, por meio de suas características naturais. Assim, os resultados encontrados são expressados por meio das ferramentas de geoprocessamento, como espacialização gráfica de cada indicador, interpolação dos dados, aplicação de geoestatística, avaliação do risco de contaminação em softwares especializados (ArcGIS, QGIS, Surfer).

O geoprocessamento pode ser definido como um conjunto de ferramentas computacionais utilizadas para o tratamento e análise de dados geográficos. Esse conjunto de ferramentas é denominado de geotecnologias composto por software e hardware (TOSTO et al., 2014). Essa ferramenta auxilia na obtenção de dados espaciais de acordo com a áreas de estudo, tais como o mapeamento das cargas contaminantes e consequente espacialização das áreas suscetíveis a contaminação e degradação. Assim, o objetivo dessa pesquisa é analisar a vulnerabilidade à contaminação hídrica de um sistema aquífero localizado na serra Olho d'água dos Constantinos no município de Redenção (CE). 


\section{METODOLOGIA}

\section{Área de estudo}

A comunidade serrana de Olho d' água dos Constantinos está localizada no distrito de Guassi, no município de Redenção, na mesorregião do norte cearense e microrregião do maciço de Baturité (Figura 1). Situa-se entre as coordenadas $4^{\circ} 14^{\prime} 47^{\prime \prime}$ de latitude Sul e $38^{\circ} 46^{\prime} 6^{\prime \prime}$ de longitude Oeste e localiza-se a aproximadamente $6 \mathrm{~km}$ da sede do município de Redenção que possui uma área de $225,63 \mathrm{Km}^{2}$ e está a 88,8 m de altitude.

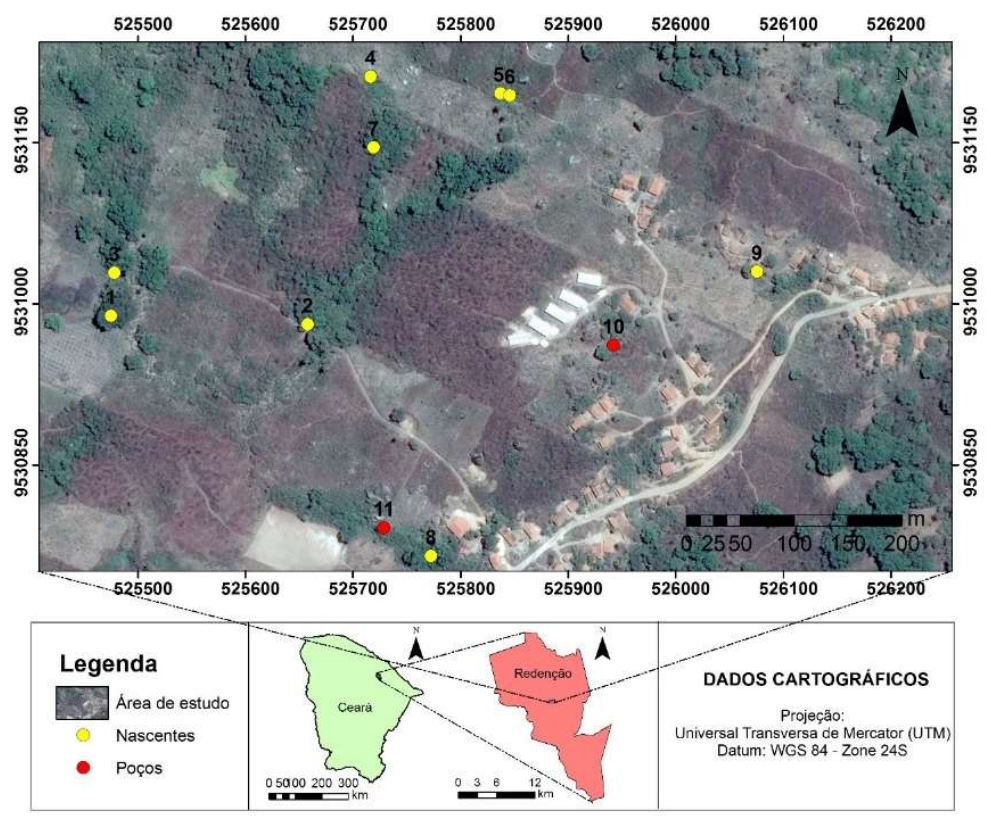

Figura 1: Localização da área de estudo.

O município encontra-se inserido na Bacia do Rio Pacoti, com relevo classificado em Maciços Residuais e Depressões Sertanejas. Apresenta clima tropical com inverno seco, caracterizado de acordo com Köppen como Aw' (GOMES SOBRINHO, 2012). A temperatura tem variação de $26^{\circ}$ a $28^{\circ} \mathrm{C}$ e precipitação de 1.062,0 mm. A vegetação nativa é Caatinga Arbustiva Densa e Floresta Subcaducifólia Tropical Pluvial. Os solos encontrados são Planossolos Solódicos e Argissolo Vermelho-Amarelado (EMBRAPA, 2013).

\section{Procedimentos metodológicos}

Os procedimentos metodológicos aplicados na pesquisa, são baseados na caracterização do uso da água; Avaliação de Impactos Ambientais (AIA) nas nascentes; vulnerabilidade natural e risco de contaminação do sistema aquífero. Os procedimentos adotados estão sumarizados no fluxograma metodológico (Figura 2) apresentado abaixo.

Para a análise situacional do recurso hídrico subterrâneo estudado, mapeou-se 11 pontos de avaliação na área de estudo, sendo 9 nascentes e 2 poços. Para tanto, percorreu-se esses locais com auxílio de um morador que conhecia a região de estudo sobre os aspectos de localização dos poços e nascentes. 0 mapeamento foi realizado com auxílio do equipamento Sistema de Posicionamento Global (GPS) modelo Garmim 76scx configurado no sistema de coordenadas Universal Transversa de Mercator (UTM) e Datum 
WGS84.

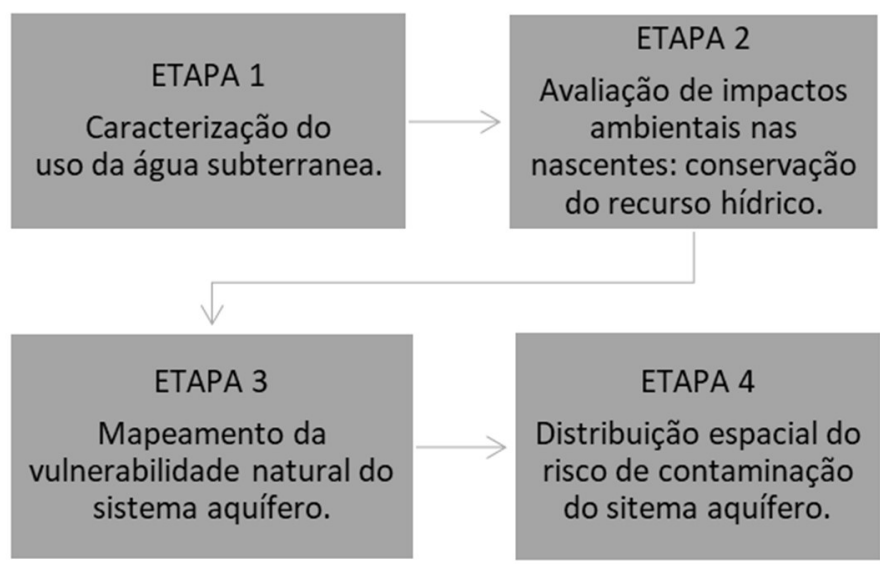

Figura 2: Procedimentos metodológicos aplicado na pesquisa.

A classificação do uso da água subterrânea na área de estudo foi realizada a partir de um questionário semiestruturado com 20 moradores, onde escolheu-se apenas um membro familiar para representar a residência, para a coleta dos dados quantitativos e qualitativos sobre a destinação da água captada pelas nascentes e poços. O questionário apresentou indagações sobre os principais usos da água, fontes de origem, forma de captação e medidas conservacionistas.

A Avaliação dos Impactos Ambientais (AIA) nas nascentes foi analisada segundo a metodologia de Oliveira et al. (2017). Esse método avalia parâmetros macroscópicos na água das nascentes e em seus arredores, cujo o objetivo é identificar as fontes de contaminação da água e ações que promovem a degradação do recurso (Tabela 1). Para tanto, analisou-se em campo as 9 nascentes a partir da tabela de avaliação no qual identificou-se a qualificação de cada parâmetro observado, conforme as especificações de cada nascente.

Tabela 1: Parâmetros de determinação do índice de impacto ambiental em nascentes.

\begin{tabular}{l|l|l|l}
\hline \multirow{2}{*}{ Parâmetros Macroscópicos } & Qualificação & Intermediário (2) & Bom (3) \\
\cline { 2 - 4 } & Ruim (1) & Clara & Transparente \\
\hline Coloração da água & Escura & Fraco & Não apresenta \\
\hline Odor da água & Forte & Pouco* & Não apresenta \\
\hline Resíduos sólidos ao redor da nascente & Muito* & Pouco & \multirow{2}{*}{ Não apresenta } \\
\hline Materiais flutuantes (Resíduos na água) & Muito & & Não apresenta \\
\hline Espumas & Muito & Pouco & Não apresenta \\
\hline Despejo de fluentes & Visível & Provável & Preservada \\
\hline Vegetação & Bastante degradada ou inexistente & Pequena alteração & Pra apresenta \\
\hline Uso antrópico (desmatamento e queimadas) & Constante & Apenas marcas & Não án \\
\hline Acesso & Fácil & Difícil & Não apresenta \\
\hline Proteção da nascente & Sem proteção & Proteção frágil & Proteção resistente \\
\hline Instalações urbanas & A menos de $50 \mathrm{~m}$ & Entre 50 a 100 m & Superior a 100 m \\
\hline
\end{tabular}

* Muito: mais da metade do espalho d'água; *Pouco: menos da metade do espalho d'água.

Fonte: Adaptado de Oliveira et al. (2017).

Após identificar a qualificação dos parâmetros, realiza-se um somatório para cada nascente, para que assim possa adequá-la no grau de preservação correspondente conforme classificação apresentada na Tabela 2. O grau de preservação varia de ótimo a péssimo. O ótimo consiste no nível máximo de preservação, cuja a nascente apresenta vegetação nativa preservada, não há atividades antrópicas nas proximidades que 
possam causar alguma poluição e degradação, a água apresenta características macroscópicas visualmente conservadas (sem resíduos sólidos, espumas, óleos, odores desagradáveis), com difícil acesso e bastante protegida.

Tabela 2: Classificação do grau de preservação das nascentes

\begin{tabular}{l|l|l}
\hline Classificação da nascente & Grau de preservação & Escala \\
\hline A & Ótimo & $31-33$ \\
B & Bom & $28-30$ \\
C & Razoável & $25-27$ \\
D & Ruim & $22-24$ \\
E & Péssimo & Igual ou inferior a 21 \\
\hline
\end{tabular}

Fonte: Adaptado de Oliveira et al. (2017).

O mapeamento da vulnerabilidade natural do aquífero foi determinado segundo Foster et al. (2003). O índice GOD considera variáveis quanto ao grau de confinamento, características litológicas e profundidade da água subterrânea (Figura 3). O índice GOD segundo Foster et al. (1988) é constituído por três variáveis G, $\mathrm{O}$ e $\mathrm{D}$, e é utilizado para estimar a vulnerabilidade natural de aquíferos à contaminação. $\mathrm{O}$ índice $\underline{\mathbf{G}}$ (Groundwater hydraulic confinement) representa o Grau de confinamento da água subterrânea e em escala varia de 0,0 a 1,0. 0 índice $\underline{\mathbf{O}}$ (Overlaying strata) representa a ocorrência de estratos de cobertura (litologia) e tem variação de 0,4 a 1,0. O índice $\underline{\mathbf{D}}$ (Depth to groundwater table) representa a distância do lençol freático até a superfície, com variação de 0,6 a 1,0.

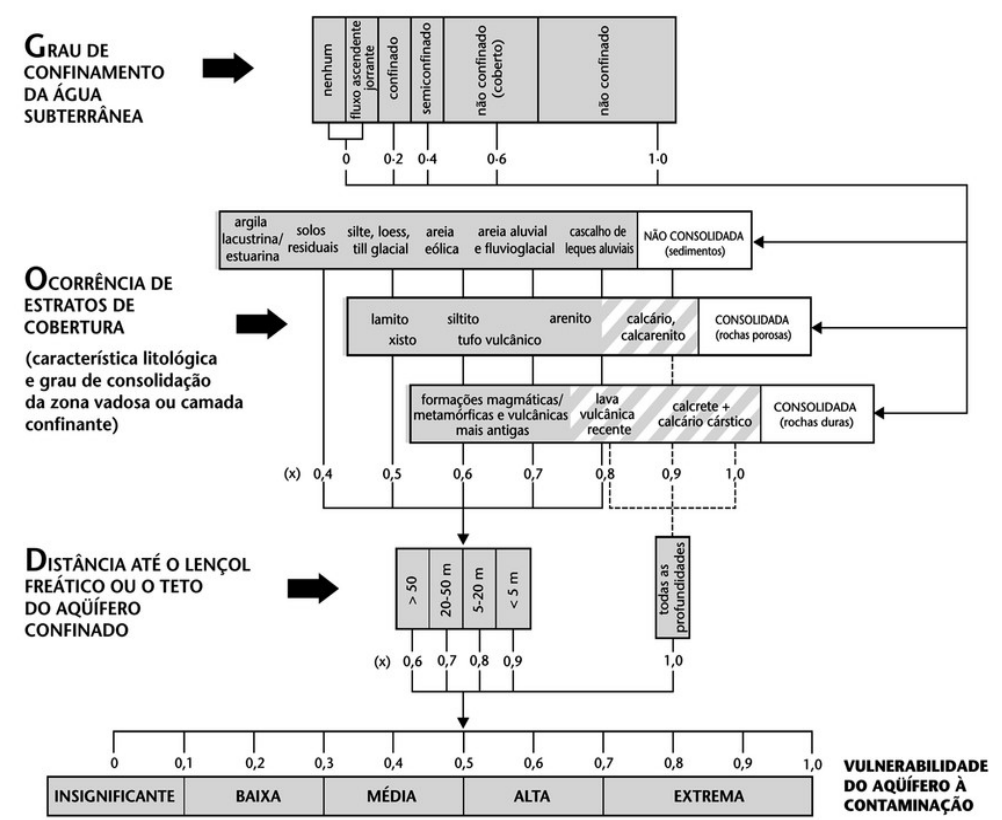

Figura 3: Método de avaliação da vulnerabilidade natural, índice GOD. Fonte: Foster et al. (2003).

Os parâmetros apresentam o mesmo peso com valores variantes de 0 a 1. Para estimar o índice de vulnerabilidade os valores dos parâmetros (G, O e D) encontrados, são multiplicados entre si e comparados na escala de vulnerabilidade apresentada pelos autores. O valor final obtido é comparado com as faixas que variam de 0 a 1 (Tabela 3), e classificam o aquífero desde a vulnerabilidade desprezível até extrema. Desse modo, os valores mais próximos de 0 corresponde a menores índices de vulnerabilidade, já valores mais próximos de 1 corresponde a maiores índices de vulnerabilidade. 
Tabela 3: Classes de significância de vulnerabilidade do aquífero.

\begin{tabular}{lll}
\hline Intervalo & Classe & Características \\
\hline $0-0,1$ & Desprezível & Desconsidera as camadas confinantes com fluxos verticais descendentes não significativos. \\
\hline $0,1-0,3$ & Baixo & $\begin{array}{l}\text { Vulnerável aos contaminantes conservativos em longo prazo, quando continuamente e amplamente } \\
\text { lançados. }\end{array}$ \\
\hline $0,3-0,5$ & Médio & Vulnerável a alguns poluentes, mas somente quando continuamente lançados. \\
\hline $0,5-0,7$ & Alto & Vulnerável a muitos poluentes, exceto aqueles pouco móveis e pouco persistentes. \\
\hline $0,7-1,0$ & Extremo & Vulnerável a muitos poluentes, com rápido impacto em muitos cenários de contaminação. \\
\hline
\end{tabular}

Fonte: Modificada de Hirata et al. (2010).

Para obter os parâmetros $\mathrm{G}$ e $\mathrm{O}$, buscou-se informações sobre os perfis construtivos/litológicos adquiridos no SIAGAS (Sistema de Informações de Águas Subterrâneas) e no CPRM (Companhia de Pesquisa de Recursos Minerais) do município de Redenção. O parâmetro D foi obtido através de medições do nível d'água dos poços na comunidade com auxílio de uma fita métrica.

Com base no parâmetro G, classificou-se o grau de confinamento nos poços em 'confinado', pois a área de estudo se localiza sob embasamento cristalino (maciço residual). Já as nascentes foram adequadas à classe de 'fluxo jorrante ascendente'. No que diz respeito ao parâmetro $O$ classificou-se a litologia em 'consolidada (rocha dura)' com formação rochosa 'magmática/metamórfica antiga'. Já o parâmetro D foi classificado de acordo com as profundidades do nível freático que variou de 2 a 6 metros. Os valores encontrados foram espacializados em um mapa de vulnerabilidade natural, assim, interpolou-se os dados por krigagem ordinária no software ArcGis 10.2.

O mapeamento de risco à contaminação da água foi determinado segundo Foster et al. (1988). A metodologia realiza o cruzamento entre a vulnerabilidade natural do aquífero com a potencialidade da carga contaminante (Figura 4). Assim, em escala, determina o grau de risco de uma determinada fonte de poluição afetar o aquífero. Os resultados do risco de contaminação da água foram interpolados por krigagem ordinária no software ArcGis 10.2, dando origem ao mapa de risco de contaminação.

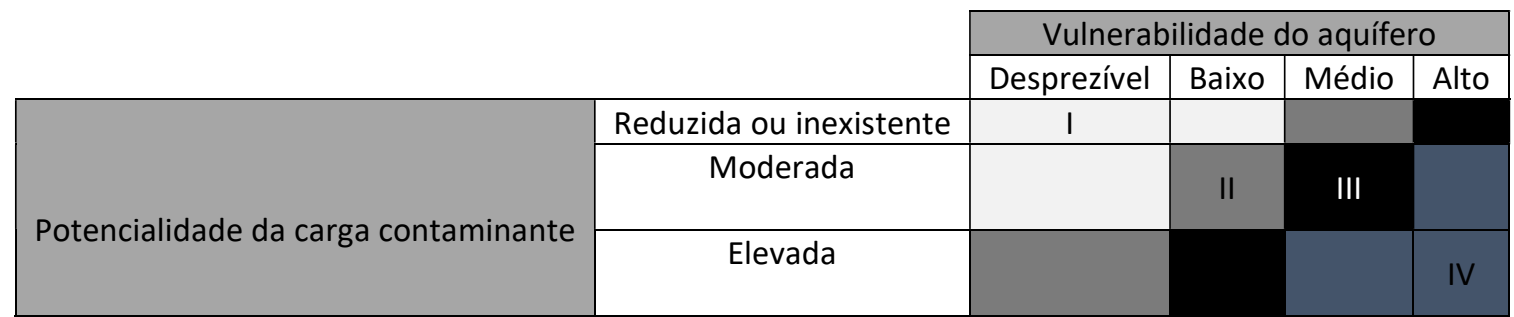

Figura 4: Classificação do risco à contaminação da água subterrânea. Fonte: Adaptado de Foster et al. (1988).

A tabela 4 sumariza as restrições de uso da água e os cuidados necessários com base em cada zona de risco identificada com o método.

Tabela 4: Categorias de riscos à contaminação de acordo com o cruzamento da vulnerabilidade natural do aquífero com a potencialidade da carga contaminante.

\begin{tabular}{|c|c|c|}
\hline $\begin{array}{l}\text { Zona de } \\
\text { risco }\end{array}$ & $\begin{array}{l}\text { Frequência de aparição do } \\
\text { risco }\end{array}$ & Cuidados para uso da água \\
\hline I & Pequena proporção & $\begin{array}{l}\text { Necessário conhecer os dados de contaminação próximo ao ponto de capitação da } \\
\text { água (raio de } 100 \mathrm{~m} \text { ) }\end{array}$ \\
\hline II & Média proporção & Restrição para alguns usos \\
\hline III & Alta proporção & Necessária investigação da qualidade da água \\
\hline IV & Elevada proporção & Necessário evitar o consumo da água \\
\hline
\end{tabular}

Fonte: Adaptado de Foster et al. (1988). 
Para estimar a carga contaminante, tomou-se como base Foster et al. (1988) o qual considera a disposição na área das cargas contaminantes que aumentam o risco potencial da contaminação. Para tanto, realizou-se uma avaliação das principais fontes de contaminação presentes na área. Mediante o quadro situacional identificado, considerou-se três meios de contaminação: efluentes, agricultura e edificações (Tabela 5). Assim, estimou-se o grau da carga contaminante em adequação ao método de análise do risco.

Tabela 5: Estimativa do grau da carga contaminante.

\begin{tabular}{|c|c|c|}
\hline $\begin{array}{l}\text { Fontes de contaminação na comunidade (dentro do raio } \\
\text { de APP das nascentes) }\end{array}$ & $\begin{array}{l}\text { Grau da carga } \\
\text { contaminante }\end{array}$ & Indicadores de classificação \\
\hline Efluentes & Moderada & Apresenta duas fontes de contaminação \\
\hline 2. Agricultura & & \\
\hline 3. Edificações & Elevada & Apresenta as três fontes de contaminação \\
\hline
\end{tabular}

\section{RESULTADOS E DISCUSSÃO}

\section{Caracterização do uso da água}

Identificou-se dentro da área de estudo 11 pontos de afloramento da água subterrânea, sendo 9 nascentes e 2 poços (Figura 5). Destaca-se que de todas as fontes hídricas, apenas as nascentes 2, 3 e 8 não são exploradas para uso da água. Desse modo, observou-se que as nascentes se encontraram em maior quantidade na região norte e oeste, regiões com maior elevação do terreno e maior dificuldade de acesso, uma vez que se identificou outras nascentes nas regiões de menor elevação que já estão secas (devido à maior facilidade de uso indiscriminado da água).

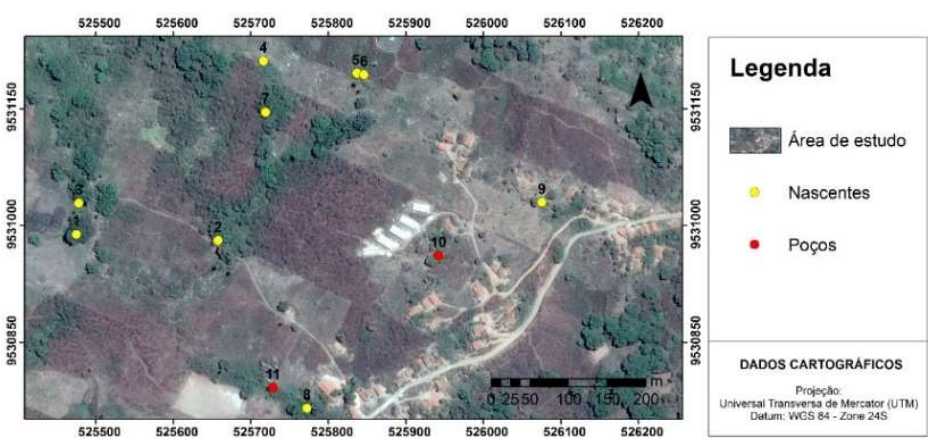

Figura 5: Localização espacial das nascentes e poços no município de Redenção-CE.

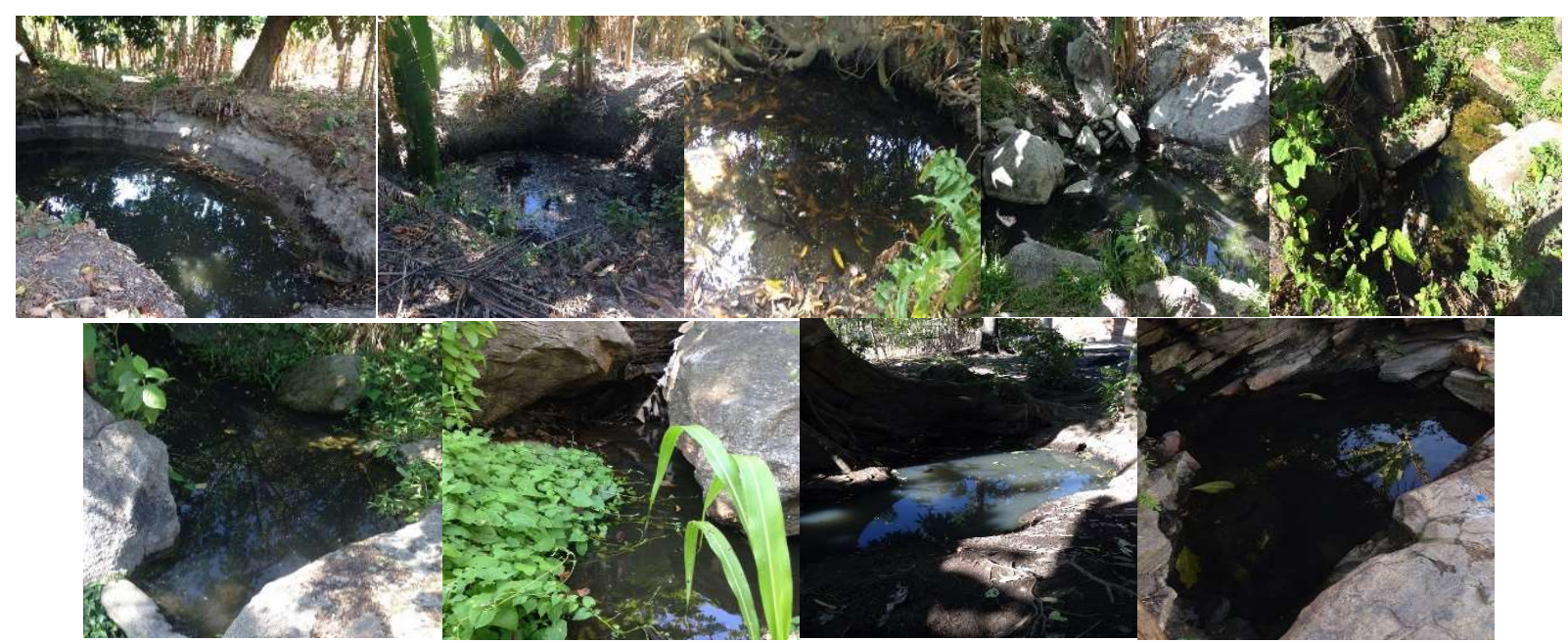

Figura 6: Nascentes analisadas da Comunidade rural: N1; N2; N3; N4; N5; N6; N7; N8 e N9. Fonte: Brito et al. (2018). 
Com base nas avaliações em campo, identificou-se que todas as nascentes apresentam algum tipo de interferência antrópica que influi direta ou indiretamente sobre a qualidade da água e conservação do recurso. As nascentes 1 e 2 encontram-se amplamente escavadas (Figura 6) para aumentar o fluxo jorrante de água para um maior aproveitamento. As nascentes 8 e 9 apresentam águas turvas pois recebem cargas de efluentes de residências bem próximas. As demais são impactadas pelas atividades agrícolas.

De acordo com a figura 7 identificou-se que a maior forma de uso da água $(45,5 \%)$ na área de estudo se dá para as atividades domésticas, sendo elas as nascentes 4, 5, 6, 9 e o poço 10. Como nem todas as residências da comunidade são beneficiárias de água encanada, o uso dessas fontes se torna imprescindíveis nas atividades rotineiras do dia-a-dia, tais como: lavagem de louça, roupas, cozinha e outras.

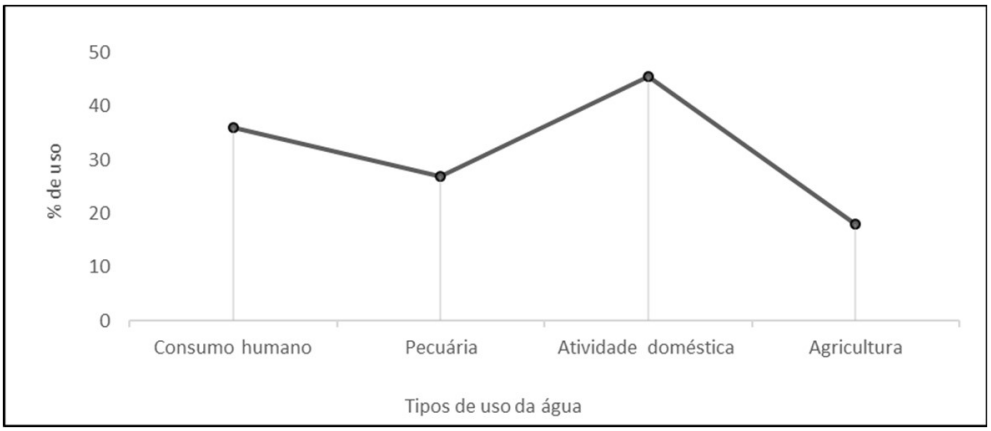

Figura 7: Uso da água subterrânea na comunidade olho d’água dos Constantinos.

A segunda maior destinação da água (36\%) foi o consumo humano, no qual de todas as fontes que são utilizadas para o uso doméstico, exceto o poço 10, também são utilizadas para o consumo. A água das nascentes 6 e 9 são retiradas manualmente in loco, já as nascentes 4 e 5 apresentam um sistema de encanamento que transporta a água até as edificações da comunidade. Como essas nascentes se encontram em alta elevação, a topografia do terreno favorece que a água seja direcionada por meio de gravidade. Malaquias et al. (2013) obtiveram resultados similares ao analisar o uso da água de nascentes em Betim-MG, onde $38 \%$ das nascentes destinavam-se ao abastecimento humano, sendo este um dos principais usos.

Observou-se que $27 \%$ das fontes de água são utilizadas para fins de pecuária, sendo as nascentes 4 e 5, que garantem a água até a comunidade. Alguns moradores usam essa água para dessedentação de animais (caprinos) e limpeza de currais. A nascente 1 é usada para dessedentação de bovinos in loco. De acordo com EMBRAPA (2014), as águas de "poços superficiais" (como é o caso das nascentes) localizados nas proximidades de áreas agropecuárias, são mais suscetíveis à contaminação por infiltração e escorrimentos superficiais.

Por outro lado, quatro nascentes são usadas para subsídio em atividades agrícolas, sendo elas a 4 e 5 , que servem para irrigação de canteiros nos quintais produtivos das residências, e a 1 e 2 , que são usadas para uso nas plantações próximas a essas nascentes. Segundo ANA (2016), no Brasil o setor de irrigação foi o que teve maior demanda consuntiva de água, seguido da dessedentação animal, tanto de água superficial como subterrânea. Com a avaliação do uso da água, identificou-se que as nascentes que mais são exploradas são a 4 e 5, cujo identificou-se aparição em 3, das 4 destinações. 


\section{AIA nas nascentes: conservação da água subterrânea}

Identificou-se que a maioria das nascentes apresentaram águas com cor aparente clara e escura, percebeu-se que as nascentes 4 e 9 apresentaram água transparente (Tabela 6). Em relação ao odor, notouse que quase todas as nascentes não apresentaram odores, em que apenas a nascente 1 apresentou odor forte. O forte odor na referida nascente estar relacionado ao apodrecimento de frutos que caem na área em que a mesma foi escavada. E também devido a decomposição de macro/microfauna na água.

Tabela 6: Resultados do índice de impactos ambientais nas nascentes.

\begin{tabular}{|c|c|c|c|c|c|c|c|c|c|}
\hline \multirow{2}{*}{ Parâmetros } & \multicolumn{9}{|c|}{ Nascentes } \\
\hline & N1 & $\mathrm{N} 2$ & N3 & N4 & N5 & N6 & N7 & N8 & N9 \\
\hline Coloração da água & 1 & 1 & 2 & 3 & 2 & 2 & 2 & 1 & 3 \\
\hline Odor da água & 2 & 1 & 3 & 3 & 3 & 3 & 3 & 1 & 3 \\
\hline Resíduos sólidos ao redor da nascente & 2 & 2 & 3 & 3 & 1 & 3 & 3 & 2 & 3 \\
\hline Materiais flutuantes (Resíduos na água) & 2 & 1 & 3 & 3 & 1 & 3 & 3 & 2 & 3 \\
\hline Espumas & 3 & 2 & 3 & 3 & 3 & 3 & 3 & 2 & 3 \\
\hline Despejo de fluentes & 3 & 3 & 3 & 3 & 3 & 3 & 3 & 1 & 1 \\
\hline Vegetação & 2 & 2 & 3 & 2 & 1 & 1 & 3 & 2 & 2 \\
\hline Uso antrópico & 1 & 3 & 3 & 2 & 3 & 3 & 3 & 2 & 1 \\
\hline Acesso & 1 & 1 & 2 & 1 & 2 & 2 & 3 & 1 & 1 \\
\hline Proteção da nascente & 1 & 1 & 1 & 1 & 2 & 3 & 3 & 3 & 2 \\
\hline Instalações urbanas & 3 & 3 & 3 & 3 & 3 & 3 & 3 & 1 & 1 \\
\hline Total & 21 & 20 & 29 & 27 & 24 & 29 & 32 & 18 & 23 \\
\hline
\end{tabular}

Percebeu-se que 55,5\% das nascentes não apresentam resíduos sólidos em suas proximidades, o que caracteriza pouca movimentação antrópica nas áreas de proximidade. Entre tanto, observou a presença de resíduos sólidos nas nascentes 1, 2, 5 e 8. A nascente 1 apresentou elevada quantidade de resíduos dispersos na água e ao redor, devido ser utilizada para agricultura, onde encontrou-se embalagens de alguns materiais agrícolas. O lixiviado, gerado nessas áreas, torna-se um dos principais elementos mais impactantes, pois causa a contaminação do solo e águas subterrâneas, pelo seu escoamento superficial ou pela percolação de substâncias (BORTOLIN et al., 2010).

Observou-se que 44,5\% das nascentes apresentam resíduos dentro da água, algumas apresentaram resíduos sólidos plásticos, entretanto, a maioria dos resíduos encontrado flutuando nas nascentes se refere aos detritos vegetais, como galhos e folhas de árvores. Observou-se que folhas e frutos de algumas culturas agrícolas também foram encontradas na água, a exemplo da bananeira, cultivada ao redor das fontes hídricas.

Em relação as espumas na água, identificou-se que 77,7\% das nascentes não há presença. Entretanto, duas nascentes apresentaram a presença desse material (em pouca quantidade), sendo elas 2 e 8. Em campo identificou-se o aparecimento de 2 fontes de contaminação por efluentes, nas nascentes 8 e 9 , ambas estão instaladas em propriedade privada. As fontes de contaminação referem-se às valas de esgoto oriundas das residências. De acordo com Pinto et al. (2012), os dejetos domésticos são fontes de transmissão de doenças e um problema para a saúde de comunidades rurais, além de serem fortes fontes de contaminação da água subterrânea.

A degradação da vegetação nativa pode impactar negativamente na conservação das nascentes. Para Oliveira et al. (2017) o desmatamento está entre os principais impactos que causam degradação a esses 
recursos hídricos. Observou-se que $77 \%$ das nascentes estão inseridas em locais cuja vegetação apresentase fortemente degradada ou há pequenas alterações. Destaca-se que a remoção total ou parcial da vegetação natural se dá principalmente para a instalação de áreas agrícolas. Os referidos autores identificaram resultados similares, uma vez que o desmatamento também é proveniente de exploração agrícola. Desse modo, salienta-se que esta é uma problemática que deve ser analisada com mais atenção, uma vez que a vegetação natural é um dos elementos que apresenta maior proteção as nascentes, por evitar o escoamento superficial, erosão do solo e atua na retenção de água no solo para o abastecimento do aquífero.

Das 9 nascentes, 5 não apresenta evidencias de desmatamento ou queimadas na vegetação ao lado das nascentes. Porém, as nascentes 1, 4, 8 e 9 apresentaram algum vestígio desse uso. De acordo com Carneiro (2017) as nascentes da serra de Redenção (CE) são impactadas por supressão vegetal oriundas principalmente por desmatamento e queimadas provenientes de atividades agrícolas na região.

Quanto ao acesso verificou-se que 55,5\% das nascentes apresentam entre fácil e difícil acesso, o que se torna mais suscetível a degradação dessas unidades. $\mathrm{O}$ acesso as nascentes se dá por trilhas bem demarcadas entre a vegetação e as áreas agrícolas. O difícil acesso em uma nascente favorece a baixa ou inexistente movimentação antrópica até o recurso, o que diminui as possíveis contaminações, o que é o caso da nascente 7.

A proteção das nascentes na área de estudo torna-se necessária, principalmente por a comunidade apresentar criação de bovinos e caprinos de modo extensivo (solto à pasto), evitando pisoteando dos animais na área. Neste sentido, 44 \% das nascentes não apresentam nenhuma proteção, como cercas, barreiras por vegetação e etc. 2 nascentes apresentam proteção frágil e 3, proteção resistente por meio de cercamento. Com exceção das nascentes 8 e 9, todas as outras (77\%) apresentam residências com localização superior a 100 metros, sendo esta uma medida conservacionista, pois diminui a degradação e contaminação do recurso por efluentes, produtos químicos ou uso inconsciente.

Com o índice aplicado, constatou-se que 33\% das nascentes apresentaram péssimo grau de conservação, em seguida, $22 \%$ foram classificadas em ruim estado de preservação (Tabela 7). Tal fato, tornase preocupante pois essas classificações representam a maior parte das nascentes, desse modo identificouse que o recurso hídrico subterrâneo se encontra em alto estado de vulnerabilidade ambiental. Apenas 11\% das nascentes classificou-se como ótimo estado de preservação. $22 \%$ apresentaram conservação boa e outra razoável. Schiavinato et al. (2019) obtiveram resultados parecidos ao aplicarem o referido método em nascentes localizadas na sub-bacia do córrego Pitas-MT. De acordo com a pesquisa, $75 \%$ das nascentes apresentaram juntas péssimo e ruim estado de conservação.

Tabela 7: Classificação do grau de preservação das nascentes.

\begin{tabular}{lll}
\hline Classificação da nascente & Grau de preservação da água subterrânea & Nascente identificada \\
\hline A & Ótimo & 7 \\
B & Bom & 3 e 6 \\
C & Razoável & 4 \\
D & Ruim & 5 e 9 \\
E & Péssimo & 1,2 e 8 \\
\hline
\end{tabular}

Identificou-se que as nascentes que apresentaram menor grau de preservação estão localizadas ao 
sul e oeste da comunidade, sendo elas as nascentes 1, 2 e 8, que classificaram péssimo grau de conservação, portanto classe "E". Ao Sul apresenta uma concentração residencial e ao oeste, área de plantação. Ao norte e noroeste da área de estudo, identificou-se as nascentes com maior grau de preservação, consequentemente os locais que apresentam maior conservação da água subterrânea (figura 8).

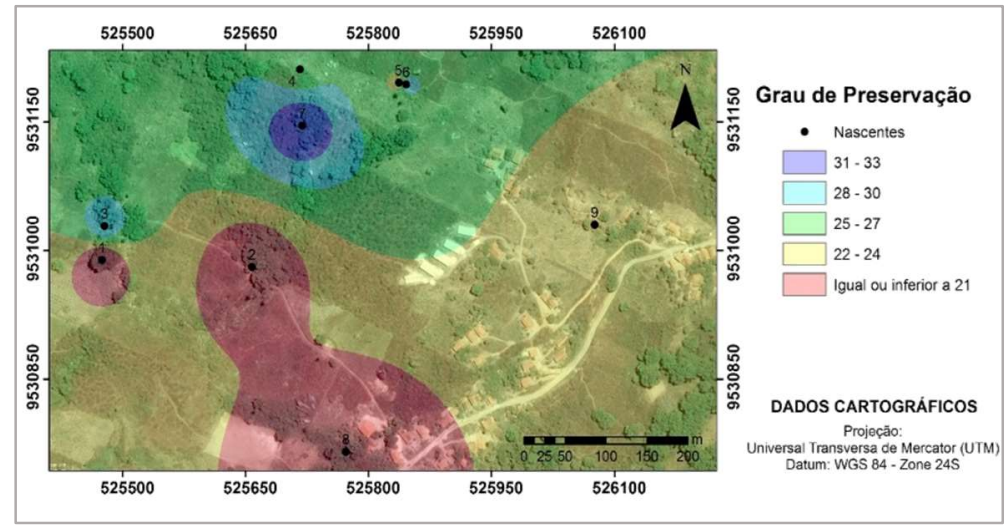

Figura 8: Mapeamento da conservação da água subterrânea.

\section{Vulnerabilidade natural do sistema aquífero}

A análise dos produtos finais gerados por meio da aplicação do índice GOD no presente estudo, nos permite identificar que a comunidade de olho d'água dos Constantinos caracteriza-se pela ocorrência da água subterrânea de forma confinada e fluxo jorrante ascendente, cujo valor do Índice $\underline{G}$ é igual a 0 e 0,2 (Tabela 8). Para Gaspar et al. (2007), as condições de artesianismo desse tipo de aquífero é controlada dentro do sistema pela presença de níveis silicificados em maiores profundidades, uma vez que a presença de vários níveis silicificados é comum no perfil dos poços em diferentes posições estratigráficas.

Tabela 8: Cálculo do índice de GOD.

\begin{tabular}{llllll}
\hline Pontos & G & O & D & GOD & Classe \\
\hline 1 & 0,2 & 0,6 & 0,9 & 0,11 & Baixo \\
2 & 0,2 & 0,6 & 0,9 & 0,11 & Baixo \\
3 & 0 & 0,6 & 0,9 & 0,00 & Desprezível \\
4 & 0 & 0,6 & 0,9 & 0,00 & Desprezível \\
5 & 0 & 0,6 & 0,9 & 0,00 & Desprezível \\
6 & 0 & 0,6 & 0,9 & 0,00 & Desprezível \\
7 & 0 & 0,6 & 0,9 & 0,00 & Desprezível \\
8 & 0,2 & 0,6 & 0,9 & 0,11 & Baixo \\
9 & 0,2 & 0,6 & 0,9 & 0,11 & Baixo \\
10 & 0,2 & 0,6 & 0,8 & 0,10 & Desprezível \\
11 & 0,2 & 0,6 & 0,8 & 0,10 & Desprezível \\
\hline
\end{tabular}

Em relação ao estrato de cobertura, identificou-se que a água subterrânea se encontra inserida sob característica litológica consolidada, com rochas duras. A litologia na área de estudo é caracterizada por maciços residuais (rochas cristalinas antigas), onde as formações das rochas são oriundas de processos magmáticos e/ou metamórficos (CPRM, 1998). Desse modo, o valor do índice $\underline{O}$ na tabela GOD classificou-se em 0,6. A litologia encontrada apresenta baixo grau de vulnerabilidade (maciço), pois possui suscetibilidade baixa a poluentes devido à baixa permeabilidade e porosidade das rochas. Desse modo, essas características dificulta a infiltração e percolação de materiais contaminantes no subsolo, que podem atingir o aquífero da comunidade e consequentemente aumentar a sua vulnerabilidade natural. 
Para o nível da água subterrânea, o índice $\underline{D}$ foi classificado em 0,9 e 0,8 onde as profundidades encontradas foram menores que 5 metros em todas as nascentes e maior que 5 metros nos poços. 0 nível da zona saturada dos aquíferos é de suma importância no processo de conservação destes, pois à medida que a água se encontra mais próxima da superfície, mais fácil fica de ser contaminada e consequentemente aumenta a suscetibilidade à degradação do recurso. Vale ressaltar que as degradações com origem antrópica são responsáveis pela variação do nível estático do aquífero. Outros fatores que podem interferir no nível estático da água são as variáveis hidrológicas, espessura da camada não saturada, composição dos materiais na zona saturada e não saturada e a topografia (MOON et al., 2004). Como a comunidade encontra-se sobre topografia bem declivosa e ondulada, a infiltração é reduzida pelo aumento do escoamento superficial.

Além disso, observou-se que as maiores vulnerabilidades se localizam na direção leste, sul e oeste (Figura 9), sendo elas as regiões que apresentaram a classe de baixo impacto. Já a classe de vulnerabilidade desprezível é distribuída em toda a área do aquífero. Desse modo, identificou-se que o aquífero não apresenta alta suscetibilidade a contaminação e degradação, pois suas características geológicas apresentam maior grau de proteção aos intemperes ambientais, com índice de 0 a 0,11. Utilizando o método GOD em Camocim no Ceará, Santos et al. (2020) identificou que o aquífero apresentou vulnerabilidade de 0,4 a 0,6.

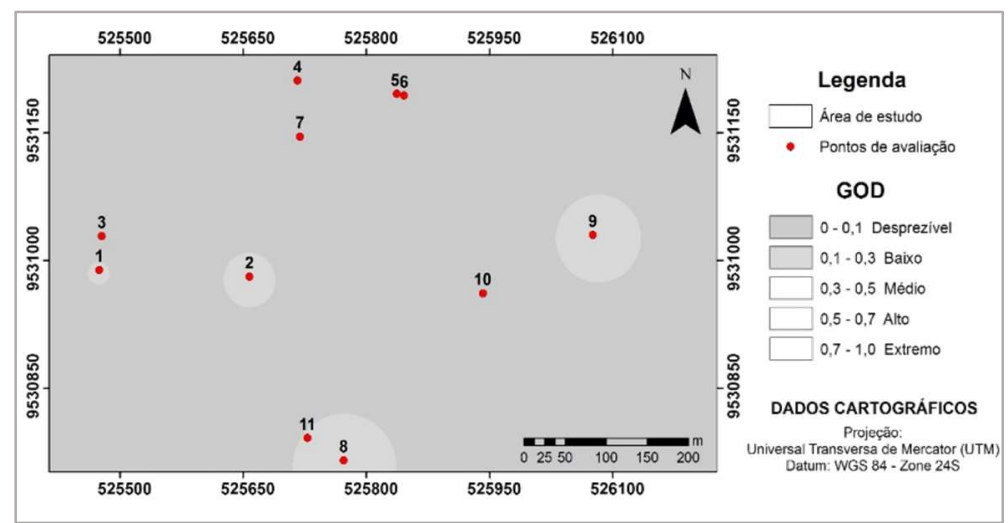

Figura 9: Mapeamento da vulnerabilidade natural do aquífero.

\section{Risco de contaminação do sistema aquífero}

Identificou-se que as principais fontes de contaminação da água subterrânea na comunidade são atividade agrícola, efluentes e edificações (Tabela 9). Desse modo, evidenciou-se que alguns locais apresentaram apenas uma fonte de contaminação, por tanto classificou-se o grau da carga contaminante em reduzida (como é o caso das nascentes 1, 2, 3, 4, 5 e 6). Os pontos que apresentaram duas e três fontes de contaminação, classificaram-se em moderado e elevado grau de contaminação, respectivamente.

Tabela 9: Resultados do grau da carga contaminante nos pontos de avalição.

\begin{tabular}{lll}
\hline Pontos de avaliação & Fontes de contaminação (Raio do $50 \mathrm{~m}, \mathrm{APP})$ & Grau da carga contaminante \\
\hline 1 & Agricultura & Reduzida \\
2 & Agricultura & Reduzida \\
3 & Agricultura & Reduzida \\
4 & Agricultura & Reduzida \\
5 & Agricultura & Reduzida \\
6 & Agricultura & Reduzida \\
7 & Não há & Inexistente \\
8 & Agricultura, efluentes, edificações & Elevada
\end{tabular}


9

10

11
Agricultura, efluentes, edificações

Edificações, efluentes

Edificações, efluentes
Elevada

Moderada

Moderada

O elevado grau de contaminação foi identificado em duas áreas, sendo elas ao sul e leste. Ao Noroeste especializou-se a inexistência de carga contaminante. Entretanto, a maior parte da área caracterizou-se por reduzido grau de contaminação, seguido da classe moderada (figura 10). Observou-se que a espacialização das fontes poluidoras apresenta relação direta com a ocupação humana na unidade estudada, cujo as áreas com suscetibilidade de contaminação foram aquelas próximas ao adensamento residencial e suas instalações. A medida que os ecossistemas naturais são ocupados pelas instalações urbanas, seus elementos (água, solo, vegetação) estarão expostos a diversas formas de degradação e contaminação. Para Silva (2013) a ocupação humana em detrimento do crescimento vertiginoso da população e consequente ampliação do uso da água subterrânea tende a reduzir a qualidade e quantidade da água disponível desses recursos.

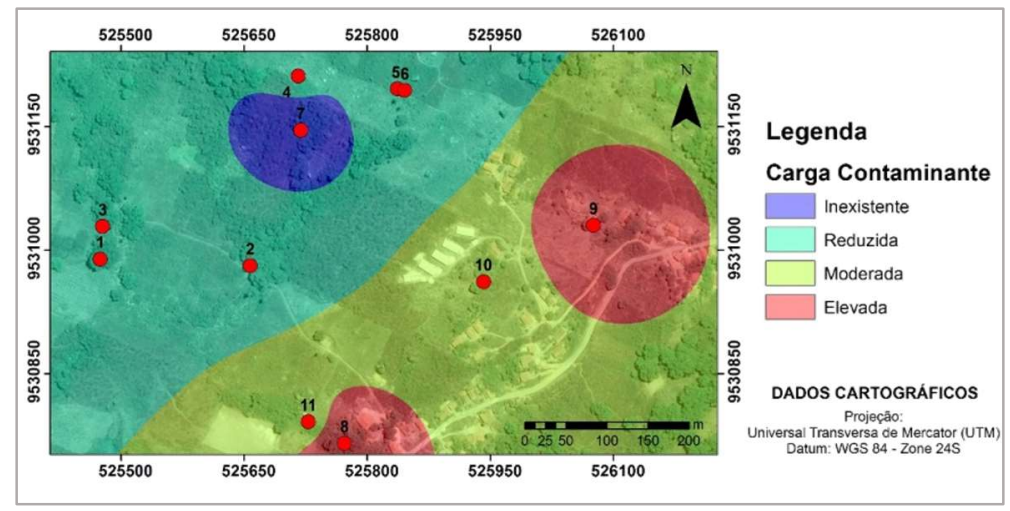

Figura 10: Mapeamento da carga contaminante na área de estudo.

Em relação ao risco de contaminação, identificou-se a presença de duas classes, risco de pequena e alta proporção. Entretanto, evidenciou-se que o risco de pequena proporção apresentou maior caracterização na área (tabela 10). Para Costa (2003), o risco de uma determinada contaminação hídrica por meio de ações danosas do homem, é função direta dos seguintes fatores: perigo, probabilidade, exposição e consequências. Por tanto, a investigação do risco deve ser realizada e discutida quando as causas da contaminação estão bem caracterizadas e o estudo visa a solução da problemática avaliada.

Assim, identificou-se que a região leste e sul apresentaram alto risco de contaminação (Figura 11), sendo essas as áreas com maior probabilidade de contaminação da água e degradação do recurso. Por tanto, esses locais devem apresentar maiores ações conservacionistas ao aquífero.

Tabela 10: Classificação do risco de contaminação da água subterrânea em cada ponto de investigação.

\begin{tabular}{llll}
\hline Ponto de avaliação & Vulnerabilidade natural do aquífero & Carga contaminante & Classificação do Risco \\
\hline 1 & Baixo & Reduzida & Pequena proporção \\
2 & Baixo & Reduzida & Pequena proporção \\
3 & Desprezível & Reduzida & Pequena proporção \\
4 & Desprezível & Reduzida & Pequena proporção \\
5 & Desprezível & Reduzida & Pequena proporção \\
6 & Desprezível & Reduzida & Pequena proporção \\
7 & Desprezível & Inexistente & Pequena proporção \\
8 & Baixo & Elevada & Alta
\end{tabular}




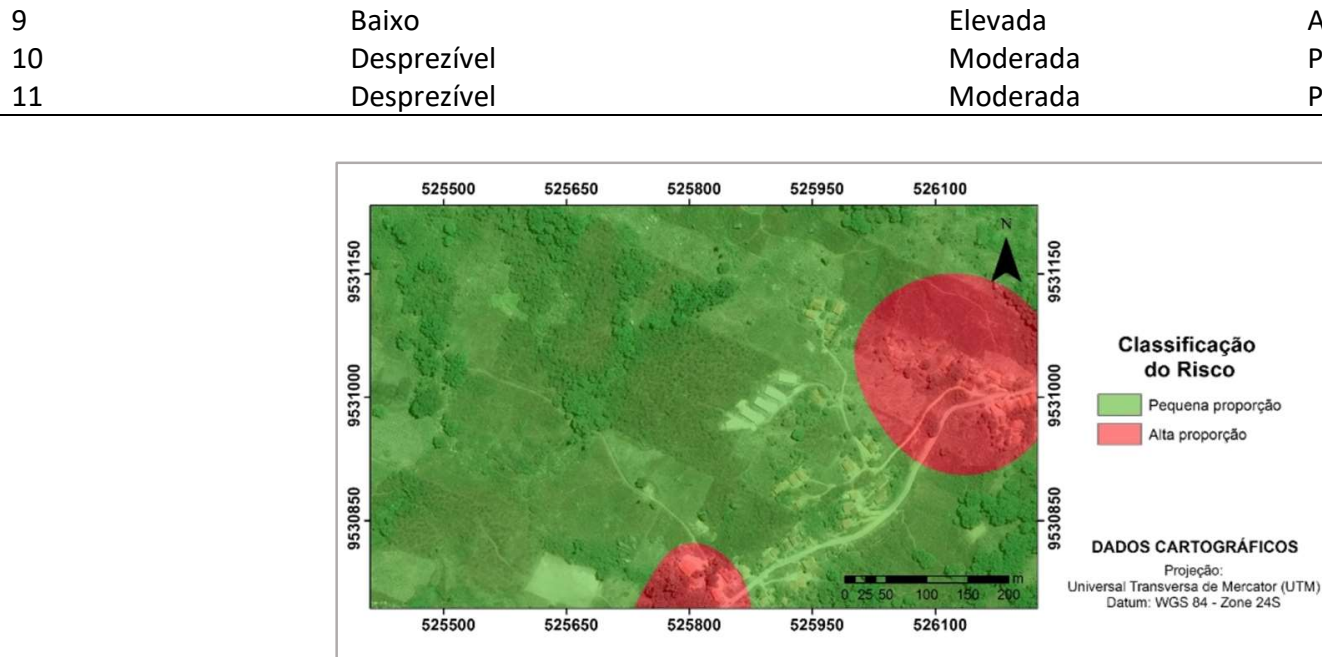

Figura 11: Mapeamento do risco de contaminação da água subterrânea.

\section{CONCLUSÕES}

A vulnerabilidade natural foi classificada em baixa e desprezível, o que representa áreas com pouca suscetibilidade a contaminação hídrica. Entretanto, observou-se a presença de cargas contaminantes com atuação direta sobre o recurso. Identificou-se que as principais fontes de contaminação da água subterrânea na comunidade são atividade agrícola, efluentes e edificações. Observou que as nascentes se encontram em baixo a médio estado de conservação e comprometem a preservação do aquífero junto a qualidade água.

Contudo, evidenciou-se que a degradação das nascentes, a presença de cargas contaminantes e o risco de contaminação hídrica, estão diretamente ligados a ocupação humana. Cujo suas instalações e desenvolvimento de atividades, são precursoras da vulnerabilidade do recurso hídrico local.

Dessa forma, conclui-se que a espacialização da vulnerabilidade junto ao mapa de risco, proporcionaram a distribuição das áreas que mais necessitam de cuidados, para que assim, possa evitar a degradação e contaminação do recurso tão necessário a comunidade e de grande importância ambiental.

O mapeamento das nascentes e dos poços na comunidade Olho d'água dos Constantinos permitiu a obtenção de informações espaciais podendo ser utilizada para auxiliar na gestão ambiental e monitoramento situacional do recurso hídrico subterrâneo.

\section{REFERÊNCIAS}

AGRIZZI, D. V.; CECÍLIO, R. A.; ZANETTI, S. S.; GARCIA, G. O.; AMARAL, A. A.; FIRMINO, E. F. A.; MENDES, N. G. S. Qualidade da água de nascentes do Assentamento Paraíso. Engenharia Sanitária e Ambiental, v.23, n.3, p.557568, 2018. DOI: http://dx.doi.org/10.1590/s1413$\underline{41522018150701}$

ANA. Agência Nacional de Águas. Conjuntura dos recursos hídricos: Informe 2016. Brasília: ANA, 2016.

BORTOLIN, J. R. M.; MALAGUTTI FILHO, W.. Método da eletrorresistividade aplicado no monitoramento temporal da pluma de contaminação em área de disposição de resíduos sólidos urbanos. Engenharia Sanitária e Ambiental, Rio de Janeiro, v.15, n.4, p.367-374, 2010. DOI:

http://dx.doi.org/10.1590/S1413-41522010000400009
BRITO, A. P.; SANTOS, I. M. M.; ALEXANDRE, L. M.; NOGUEIRA, R. S.. Distribuição espacial das nascentes e análise da qualidade da água na comunidade olho d'água dos Constantinos, em Redenção, Ceará. In: SIMPÓSIO REGIONAL DE GEOPROCESSAMENTO. Anais. Teresina: IFPI, 2019.

CARNEIRO, F. J. B.. Mapeamento do uso de agrotóxicos e da qualidade da água de nascentes na comunidade rural de Piroás, Redenção - CE. Monografia (Especialização) Universidade da Integração Internacional da Lusofonia Afrobrasileira, Redenção, 2017.

CPRM. Companhia de Pesquisa de Recursos Minerais. Programa de recenseamento de fontes de abastecimento 
por água subterrânea no Estado do Ceará: diagnóstico do município de Redenção. Fortaleza: CPRM, 1998.

EMBRAPA. Empresa Brasileira de Pesquisa Agropecuária. Qualidade da água na produção animal. São Carlos: EMBRAPA, 2014.

EMBRAPA. Empresa Brasileira de Pesquisa Agropecuária. Sistema brasileiro de classificação de solos. Centro Nacional de Pesquisa de Solos. Rio de Janeiro: EMBRAPA, 2013.

FOSTER, S. S. D.. Fundamental concepts in aquifer vulnerability, pollution risk and protection strategy. In: VAN DUIJVANBOODEN, W.; VAN WAEGENINGH, H. G..

Vulnerability of Soil and Groundwater to Pollution, Proceedings and Information No. 38 of the International Conference held in the Netherlands. Delft: TNO Committee on Hydrological Research, 1987.

FOSTER, S. S. D.; HIRATA, R. C. A.. Determinacion del Riesgo de Contaminacion de Águas Subterrâneas: una metodologia basada en datos existentes. Lima: Organizacion Mundial de La Salud, 1988.

FOSTER, S.; HIRATA, R.; GOMES, D.; D'ELIA, M.; PARIS, M.. Protección de La Calidadd el Água Subterránea: guía para empresas de água, autoridades municipals y agencias ambientales. Washington: Banco Mundial, 2003.

GASPAR, M. T. P.; CAMPOS, J. E. G.. O Sistema Aquífero Urucuia. Revista Brasileira de Geociências, v.37, n.4, p.216226, 2007.

GOMES SOBRINHO, T. R. G.. Classificação climática conforme a metodologia Köppen do município de Laranjal do Jari/Amapá/Brasil. In: CONGRESSO NORTE NORDESTE DE PESQUISA E INOVAÇÃO - CONNEPI, 7. Anais. Palmas, 2012.

HIRATA, R.; ZOBY, J. L. G.; OLIVEIRA, F. R.. Água subterrânea: reserva estratégica ou emergencial. In: BICUDO, C. E. M.; TUNDISI, J. G.; SCHEUENSTUHL, M. C. B.. Águas do Brasil: análises estratégicas. São Paulo: Instituto de Botânica, 2010. p.149-161.

LIMA, A. A. G.. Insegurança hídrica domiciliar em comunidades suscetíveis a seca no município de Maranguape - CE. Tese (Doutorado em Geografia) -
Universidade Federal do Ceará, Fortaleza, 2020.

MALAQUIAS, G. B.; CÂNDIDO, B. B.. Avaliação dos impactos ambientais em nascentes do munícipio de Betim, MG: análise macroscópica. Revista Meio Ambiente e Sustentabilidade, v.3, n.2, p.51-65, 2013.

MOON, S.; WOO, N. C.; KWANG, G. L.. Statistical analysis of hydrographs and water-table fluctuation to estimate groundwater recharge. Jounal of Hydology, v.292, p.198209, 2004.

OLIVEIRA, J. A.; TEIXEIRA, V. L.; ALVES, S.. Atlas da Região Hidrográfica Médio Paraíba do Sul. Comitê Médio Paraíba do Sul, 2017.

PIERONI, J. P.; BRANCO, K. G. R.; DIAS, G. R. V.; FERREIRA, G. C.. Avaliação do estado de conservação de nascentes em microbacias hidrográficas. Revista Geociências, São Paulo, v.1, n.38, p.185-193, 2019.

PINTO, L. V. A.; ROMA, T. N.; BALIEIRO, K. R. C.. Avaliação qualitativa da água de nascentes com diferentes usos do solo em seu entorno. Cerne, Lavras, v.18, n.3, p.495-505, 2012.

SANTOS, I. M. M.; BRITO, A. P. M.; SILVA, R. M.. Utilização do método GOD para análise da vulnerabilidade natural de águas subterrâneas na comunidade de Xavier e seu entorno em Camocim/CE. Revista Homem, Espaço e Tempo, v.14, n.1, p.145-163, 2020.

SCHIAVINATO, V. M. S.; GONZALEZ, A. Z. D.. Avaliação ambiental de nascentes na sub-bacia hidrográfica do córrego das Pitas-MT, Brasil. Revista Equador, v.8, n.3, p.260-278, 2019.

SILVA, W. F.. Análise da vulnerabilidade das águas subterrâneas à contaminação na região metropolitana de Maceió. Dissertação (Especialização em Recursos Hídricos e Saneamento) - Universidade Federal de Alagoas, Alagoas, 2013.

TOSTO, S. G.; RODRIGUES, C. A. G.; BOLFE, E. L.; BATISTELLA M.. Geotecnologias e Geoinformação: o produtor pergunta, a Embrapa responde. Brasília: EMBRAPA, 2014.

A CBPC - Companhia Brasileira de Produção Científica (CNPJ: 11.221.422/0001-03) detém os direitos materiais desta publicação. Os direitos referem-se à publicação do trabalho em qualquer parte do mundo, incluindo os direitos às renovações, expansões e disseminações da contribuição, bem como outros direitos subsidiários. Todos os trabalhos publicados eletronicamente poderão posteriormente ser publicados em coletâneas impressas sob coordenação da Sustenere Publishing, da Companhia Brasileira de Produção Científica e seus parceiros autorizados. Os (as) autores (as) preservam os direitos autorais, mas não têm permissão para a publicação da contribuição em outro meio, impresso ou digital, em português ou em tradução. 